\title{
Visual Assessment of Surface Fuel Loads Does Not Align with Destructively Sampled Surface Fuels
}

\author{
Sarah C. McColl-Gausden * (1) and Trent D. Penman \\ School of Ecosystem and Forest Sciences, University of Melbourne, 4 Water Street, Creswick, VIC 3363, Australia; \\ trent.penman@unimelb.edu.au \\ * Correspondence: mccoll.s@unimelb.edu.au; Tel.: +61-5321-4196
}

Received: 16 September 2017; Accepted: 26 October 2017; Published: 27 October 2017

\begin{abstract}
Fuel load and structure are fundamental drivers of fire behaviour. Accurate data is required for managers and researchers to better understand our ability to alter fire risk. While there are many ways to quantify fuel, visual assessment methods are generally considered the most efficient. Visual hazard assessments are commonly used by managers, government agencies and consultants to provide a fuel hazard score or rating but not a quantity of fuel. Many systems attempt to convert the hazard score or rating to a fuel load for use in fire behaviour models. Here we investigate whether the conversion table in the widely used Overall Fuel Hazard Guide (OFHG) matches destructively sampled fuel loads from 116 sites across five forest types. We specifically examine whether there are quantifiable differences that can be attributed to forest type. We found there is overlap between the two methods for low, moderate and high hazard categories, however for the very high and extreme hazard categories, visual assessment overestimated fuel load in four of the five forest types. Using a commonly applied fire behaviour model, we found that the overestimation of fuel load in very high and extreme hazard categories leads to an overestimation of fire behavior in these hazard categories.
\end{abstract}

Keywords: visual fuel assessments; fuel load estimates; bushfire; wildfire; fire behaviour; fire risk; fine fuel; fire management

\section{Introduction}

Fuel is one of the key drivers for fire at multiple scales. [1]. Widely used empirical fire behaviour models incorporate measures of fuel load or structure [2-4]. Most forest fire behaviour models require fine fuel load-fuel particles $<6 \mathrm{~mm}$ diameter-as the primary fuel input. [5,6]. In order to predict fire behaviour, efficient and accurate methods are required to quantify fine fuel loads across landscapes.

A range of methods for assessing fine fuel loads exist including destructive sampling, visual assessment, the line intercept method and remote sensing [7-9]. Destructive sampling is costly and time consuming but is considered the most reliable method for estimating fuel loads [10]. Globally, visual assessment methods have been developed to rapidly estimate fuel loads [11-13] which match the inputs required for the specific fire behaviour models [14]. However, the subjective nature of many of the visual assessment approaches has been found to result in large variability in fuel estimates at a single site [15].

There are two systems of visual fuel assessment in Australia—the Overall Fuel Hazard Assessment Guide (OFHG) [16] and the Project Vesta guide [17]. Both systems rate or score individual fuel layers in terms of the level of "hazard". The OFHG is used to make a rapid assessment of fuel arrangement. In the OFHG, fuel is divided into surface, near-surface, elevated and bark fuel layers. Each fuel layer is assigned a fuel hazard rating (low, moderate, high, very high or extreme) by visually examining key attributes such as percentage cover, percentage of dead fuel, and horizontal and vertical continuity of the fuel layer. An overall fuel hazard rating for the site is calculated using the fuel hazard ratings 
of the individual fuel layers. Visual fuel hazard ratings can be converted to fuel loads and applied in operational fire behaviour models $[18,19]$. A recent study found a poor relationship between destructively sampled fuel loads and visual fuel hazard ratings converted to fuel loads, across a broad range of eucalyptus forest types [20]. However, the study did not explicitly account for forest types in their analysis.

Surface fuel loads and vegetation types vary across productivity gradients [21]. Accounting for these variations may allow for improvements in the conversion of visual fuel hazard ratings to fuel load and thereby improve our ability to model fire behaviour and risk. In this study, we compare surface fuel load estimates using both destructive sampling and converted visual fuel hazard ratings using the OFHG across five major forest types. Specifically, we ask (1) do the converted fuel loads calculated from visual fuel hazard ratings approximate destructively sampled fuel loads? (2) Is there a systematic error in the converted fuel load that could be attributed to forest type? (3) How do any differences in fuel loads calculated from visual fuel hazard ratings versus destructive sampling affect simple fire behaviour predictions.

\section{Materials and Methods}

The study was conducted in the Otway ranges, a 59,000-ha area in southern Victoria, Australia. Five broad forest types were identified in this area which represent groupings of vegetation that exhibit similar ecological characteristics such as response and tolerance to fire [22]. Heathland is dominated by sclerophyllous shrubs and can include scattered trees of different Eucalyptus species (E. obliqua (L'Hér.), E. falciformis (Newnham, Ladiges \& Whiffin) Rule, and E. baxteri (Benth.)). Tall Mixed forests are dominated by E. obliqua and E. baxteri in the overstory with an understory of tussock grasses and low shrubs. Foothills forests are dominated by E. obliqua, E. cypellocarpa (L.A.S. Johnson), with an understory dominated by wire grass Tetrarrhena juncea (R. Br.) and dense shrubs. Forby forests have an overstory dominated by E. obliqua, E. cypellocarpa, and E. radiata (Sieber ex DC.) with grasses and forbs in the understory. Wet forests tend to have a tall overstory mostly dominated by E. obliqua and E. cypellocarpa. Acacia melanoxylon (R. Br.) often forms a dense midstory layer and tall shrubs dominate the understory. The distribution of vegetation is driven strongly by a rainfall productivity gradient. Heathland occurs in low-lying dry areas in the northeast, $0-250 \mathrm{~m}$ above sea level with approximately $624 \mathrm{~mm}$ annual rainfall. The wet forests are located in areas in the southwest at higher elevations of approximately $650 \mathrm{~m}$ above sea level with $1259 \mathrm{~mm}$ of annual rainfall [23]. A total of 116 sites were surveyed with post fire ages from 1 to 78 years (for detailed site description see Table 1 and Sitters, et al. [24]).

Surface fine fuel load was examined at each site within a circular plot $25 \mathrm{~m}$ in radius using both a visual approach and destructive sampling. At each site, the OFHG was used to visually assign a fuel hazard rating to the surface fuel layer using a single trained assessor for all sites. The visual fuel hazard rating was converted to a fuel load based on the OFHG $[16,25]$. Destructive samples of the surface fine fuel were collected at two random points within each site using $0.1 \mathrm{~m}^{2}$ circular quadrats. These samples were considered sufficient to capture the variation within the larger plot without causing significant environmental damage. Surface fine fuel was defined as all flammable material (twigs, fallen leaves, bark, and dried vegetation) $<6 \mathrm{~mm}$ diameter at ground level. Samples were dried at $105{ }^{\circ} \mathrm{C}$ for a minimum of $48 \mathrm{~h}$ until a constant weight was achieved. Values were converted to tonnes/hectare ( $t / h a)$ (see [26]).

To compare the converted fuel loads from the visual fuel hazard rating and destructively sampled fuel loads, we used a confidence interval approach [27]. Means and $95 \%$ confidence intervals were calculated for the destructively sampled fuel loads. These results were categorised by the fuel hazard rating assigned to the surface fuel and the forest type. Values were deemed to be significantly different at the $p=0.05$ level if the $95 \%$ confidence intervals did not overlap with the range of converted fuel loads given in the OFHG [16]. 
To determine if there is a systematic error in the converted fuel load that could be attributed to vegetation formation we use a two-factor analysis of variance. The response variable was the square root of the destructively sampled surface fuel load and the two predictor variables were the surface fuel hazard rating and forest type. Destructively sampled surface fuel load was transformed to fulfil the assumptions of normality and homogeneity of variances [28]. A Tukey's honest significant difference test examined differences between groups for significant results. All analyses were conducted using the R statistical package v3.3.2 [29].

To examine the effect on fire behaviour of any differences in fuel loads calculated from visual fuel hazard ratings versus destructive sampling, we used the McArthur fire behaviour equations as stated by Noble, et al. [30] to estimate rate of spread (ROS), flame height (FH) and intensity (INT). The equations require inputs of the Forest Fire Danger Index (FFDI), slope and weather. FFDI is a fire weather index that accounts for temperature, relative humidity, wind speed and a long term drying index. Varying FFDI did not affect the outcome of the analysis and therefore for simplicity we held FFDI at a constant value of 50. Slope was held at a constant value of 0 throughout to remove topographic effects. Converted fuel loads from the OFHG were taken as the minimum and maximum for the range given in Hines, et al. [16]. We used the mean and 95\% CI values of the destructively sampled fuel loads. Significant differences was determined by non-overlapping CI as per Walshe, et al. [27].

\section{Results}

Destructively sampled surface fuel loads varied from $0.30 \mathrm{t} / \mathrm{ha}$ in heathland to $23.33 \mathrm{t} / \mathrm{ha}$ in foothills forest (Table 1). None of the heathland sites were assessed as having very high or extreme fuel hazard. No wet forest sites were assessed as having low or extreme fuel hazard. No tall mixed sites were assessed as having extreme fuel hazard.

Table 1. Summary of sampling sites and results across the five forest types for destructively sampled fuel loads (Mean fuel load) and the visual fuel hazard rating (Median fuel hazard rating). Values in brackets represent the range of sampled values.

\begin{tabular}{ccccc}
\hline Forest Type & Number of Sites & Post-Fire Age Range & Mean Surface Fuel Load (t/ha) & Median Surface Fuel Hazard Rating \\
\hline heathland & 25 & $2-34$ & $4.45(0.30-11.10)$ & Low (Low-High) \\
tall mixed & 26 & $2-34$ & $8.24(2.86-16.58)$ & Moderate (Low-Very High) \\
foothills & 26 & $1-78$ & $9.73(2.74-23.33)$ & High (Low-Extreme) \\
forby & 20 & $5-78$ & $6.78(1.25-17.99)$ & Moderate (Low-Extreme) \\
wet & 19 & $5-58$ & $10.42(5.16-17.52)$ & High (Moderate-Very High) \\
\hline
\end{tabular}

Significant differences were seen between the destructively sampled fuel load and the converted fuel load with the largest differences seen in the very high and extreme categories (Figure 1). Destructively sampled fuel loads were significantly higher than the converted fuel load for the tall mixed forest sites in the low hazard category, but no significant differences occurred in the heathland, forby forest or foothills forest. No significant differences were seen between the methods for moderate and high fuel hazard ratings. This result was consistent for all five forest types. In the very high category, all sampled forest types had significantly lower destructively sampled fuel loads than the converted fuel load values. Few sites were classed as having extreme fuel hazards. The one forby site classed as extreme had significantly lower destructively sampled fuel loads than predicted by visual assessment. Mean destructively sampled fuel load values for foothills forests were outside the predicted range given in the OFHG but there was considerable variability suggesting non-significant differences at the $p=0.05$ level. 


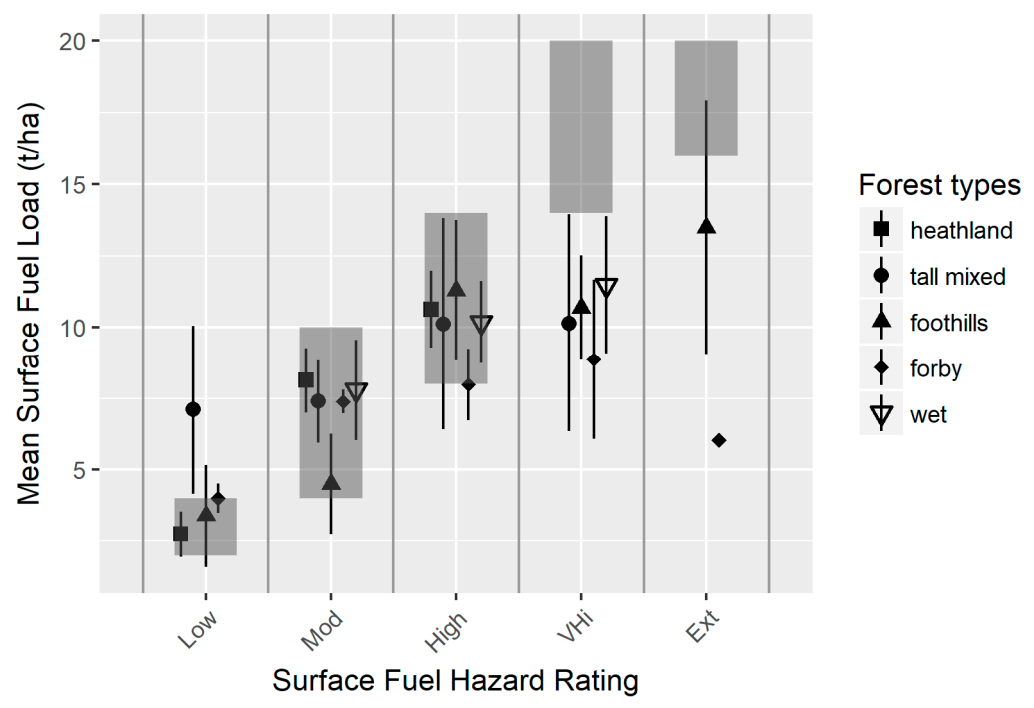

Figure 1. Mean destructively sampled surface fuel loads ( $\mathrm{t} / \mathrm{ha}$ ) (symbols) with $95 \%$ confidence intervals by fuel hazard ratings: Low, Moderate (Mod), High, Very High (VHi) and Extreme (Ext). Grey bars represent the range of converted fuel loads from the Overall Fuel Hazard Guide.

Significant differences were seen in the destructively sampled fuel load between fuel hazard classes $(\mathrm{F} 4=22.6133 p<0.0001)$ but not forest types $(\mathrm{F} 4=1.3096 p=0.2719)$ and the interaction was not significant $(\mathrm{F} 11=1.3575 p=0.2058)$. Post hoc testing using Tukey's HSD test found significant differences between the low, moderate and high hazard classes but not the very high or extreme hazard classes (Figure 2). Sites assessed as having a low surface hazard had destructively sampled fuel loads significantly lower than all other classes (Moderate $p<0.0001$, High $p<0.0001$, Very High $p<0.0001$, Extreme $p<0.0001)$. Destructively sampled fuel loads in sites with moderate surface hazard were significantly lower compared with the high $(p=0.0371)$ and very high $(p=0.0418)$ hazard sites but not the extreme hazard sites $(p=0.1468)$. The mean fuel load values for the High, Very High and Extreme values were clustered with minimal difference between them; $10.04 \mathrm{t} / \mathrm{ha}, 10.30 \mathrm{t} / \mathrm{ha}, 9.76 \mathrm{t} / \mathrm{ha}$ respectively (Figure 2).

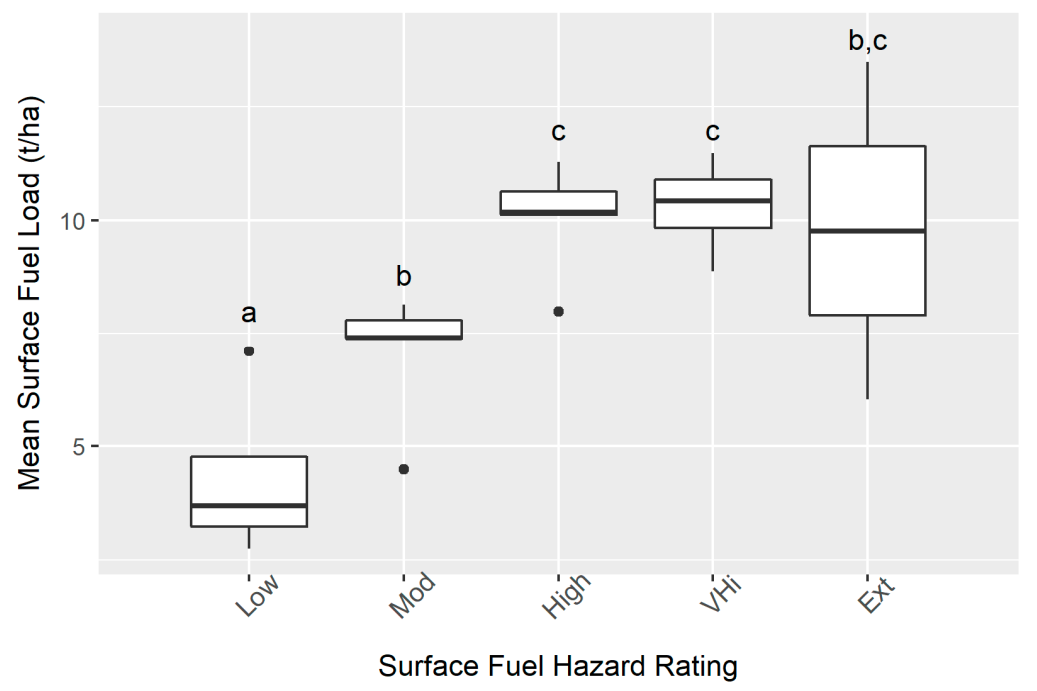

Figure 2. Destructively sampled surface fuel loads ( $t /$ ha) by fuel hazard rating. Box indicates the median (bold line) with lower and upper quartiles (25\% and $75 \%)$. Whiskers indicate the minimum and maximum values that are not outliers (dots). Letters represent significantly different results. 
The method for quantifying fuel load did not have a significant effect on any of the fire behaviour metrics tested (ROS, FH, INT) for the low, moderate and high surface fuel hazard categories (Figure 3). In the very high surface fuel hazard category, there was no significant difference between fire behaviour estimates from the destructively sampled fuel load and the converted fuel load. However, when using the median values from the OFHG for the very high hazard category, fire behaviour metrics were significantly higher than the estimates for the destructively sampled fuel loads. In the extreme surface fuel hazard category, the OFHG significantly overestimates ROS by between 0.36 and $0.63 \mathrm{~km} / \mathrm{h}$, intensity by between 5689 and $8429 \mathrm{~kW} / \mathrm{m}$ and flame height by between 6.1 and $10.72 \mathrm{~m}$ using the median fuel load from the OFHG.
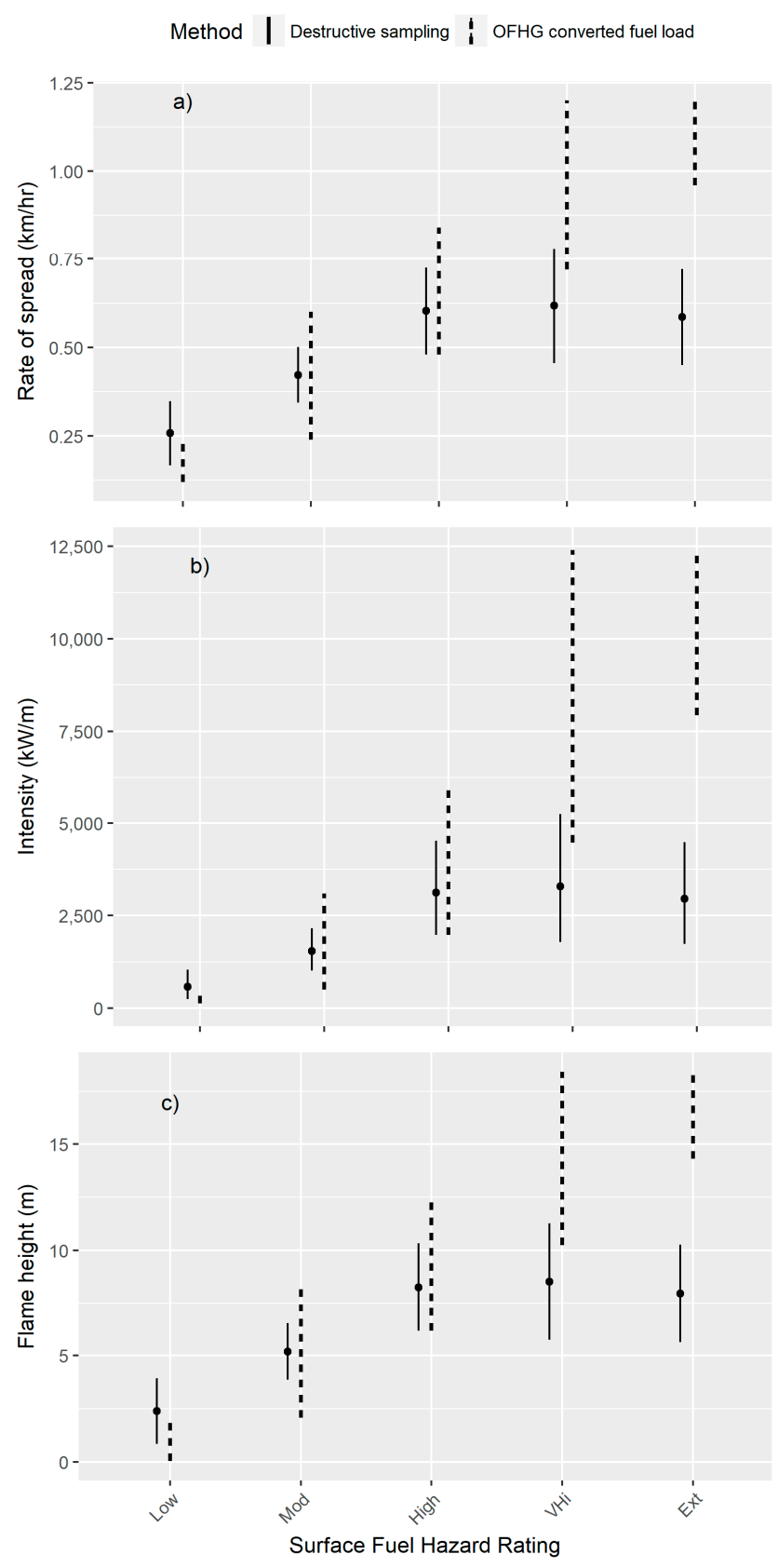

Figure 3. Fire behavior by fuel hazard category: Low, Moderate (Mod), High, Very High (VHi) and Extreme (Ext) for mean destructively sampled surface fuel loads ( $/$ ha) (symbols) with $95 \%$ confidence intervals (solid line) and the converted fuel loads taken as the minimum and maximum for the range given in the OFHG (dashed line). (a) Rate of spread $(\mathrm{km} / \mathrm{h}),(\mathbf{b})$ intensity $(\mathrm{kW} / \mathrm{m})$ and (c) flame height $(\mathrm{m})$. 


\section{Discussion}

Fuel loads derived from a visual fuel hazard rating in the OFHG aligned with destructively sampled fuel loads in the low, moderate and high hazard categories. In sites deemed to be of very high or extreme hazard, the converted fuel load was inaccurate and an overestimation of fuel load. These results are consistent with the previous study by Volkova, Sullivan, Roxburgh and Weston [20] despite a smaller sampling effort for destructively sampled fuel loads. In our study, at sites measured as high or above, the destructively sampled fuel loads were not statistically different.

Surface fuel load is a common input for fire behaviour models that are routinely used as the basis for fire management decisions. Many relationships have been built using fuel load rather than hazard scores or ratings $[4,5,30]$. However, hazard ratings are commonly converted to fuel loads and these models are in common use operationally and strategically in many Australian states [18,31]. Within these models, the rate of spread, intensity and flame height increase with increasing surface fuel loads if everything else is held constant [30,32]. We have shown that a commonly applied fire behavior model, the McArthur fire behaviour model, overestimates fire behaviour for sites classed as having very high or extreme surface fuel hazard if the converted fuel loads from the OFHG are used. This is due to the overestimation of surface fuel load by hazard rating in the very high and extreme categories.

These fire behaviour models have been used to examine fire risk in response to changing fuel hazard. Examples include studies of the role of changing fuel types through regeneration $[33,34]$, reducing fuel hazard through fuel treatment [35] or changing risk from fire over time [36]. Generally, these studies have assumed increasing fuel hazard with increasing time since fire. These studies may overestimate the role of fuel management in reducing risk due to the overestimation of fuel load in older fuels.

Fuel loads are known to vary between vegetation types [21] but we found no evidence of varying fuel load within fuel hazard ratings between forest types tested. Differences were only seen in the range of values achieved within a vegetation community. For example, the fuel hazard rating for the oldest heathland sites did not exceed a high hazard rating. Similarly, the wet forests were never lower than moderate hazard types. Despite sampling within a geographically restricted area, the range of forest types was broad covering $1 \mathrm{~m}$ tall heathland through to $50 \mathrm{~m}$ tall wet forest. Our results suggest that the OFHG is relatively robust to vegetation type and with caution can be applied more broadly as a guide (given the caveats above).

Perhaps the greatest limitation of the visual fuel assessment methods is the lack of a direct link to fire behaviour models. Many of the relationships between fuel hazard ratings and fire behaviour are based on expert opinion rather than empirical research (but see Cheney, et al. [19]). While there is increasing acceptance in the use of experts in the development of a range of environmental models [37-41], formal elicitation requires careful design and interpretation [41,42] which appears lacking in these guides. Some recent fire behaviour models have been proposed based on direct relationships with hazard ratings or scores $[17,19]$. Future fire behaviour research would therefore benefit from considering multiple direct and indirect fuel measurements to not only optimise the model but also increase our ability to rapidly collect data for landscape prediction of fuels.

\section{Conclusions}

We compared destructively sampled fuel loads with fuel loads converted from visual fuel hazard ratings using the OFHG across five major forest types where the OFHG is applicable. Converted fuel loads approximate destructively sampled fuel loads in the low, moderate and high surface fuel hazard categories but overestimate fuel load compared to destructively sampled fuel loads in the very high and extreme surface fuel hazard categories. We found no evidence of systematic error that could be attributed to forest types. Using fuel loads converted from visual fuel hazard ratings in the OFHG led to an overestimation of fire behavior metrics in sites deemed to be of very high or extreme surface fuel hazard. 
Acknowledgments: The work was funded by a student scholarship from the School of Ecosystem and Forest Sciences, University of Melbourne to S.C.M.-G. Discussions with Kevin Tolhurst, Thomas Duff and Jane Cawson aided in the development of this paper. We thank Matthew Swan, Holly Sitters, Julian di Stefano and Alan York for access to their study sites and associated site data.

Author Contributions: S.C.M.-G. and T.D.P. conceived and designed the field survey; S.C.M.-G. performed field survey; both authors contributed to the analysis of data and the writing of the paper.

Conflicts of Interest: The authors declare no conflict of interest.

\section{References}

1. Bradstock, R.A. A biogeographic model of fire regimes in australia: Current and future implications. Glob. Ecol. Biogeogr. 2010, 19, 145-158. [CrossRef]

2. Sullivan, A.L. Wildland surface fire spread modelling, 1990-2007. 1: Physical and quasi-physical models. Int. J. Wildland Fire 2009, 18, 349-368. [CrossRef]

3. Sullivan, A.L. Wildland surface fire spread modelling, 1990-2007. 2: Empirical and quasi-empirical models. Int. J. Wildland Fire 2009, 18, 369-386. [CrossRef]

4. Cruz, M.G.; Gould, J.S.; Alexander, M.E.; Sullivan, A.L.; McCaw, W.L.; Matthews, S. Empirical-based models for predicting head-fire rate of spread in australian fuel types. Aust. For. 2015, 78, 118-158. [CrossRef]

5. McArthur, A.G. Fire Behaviour in Eucalypt Forests. Leaflet No. 107; Forest Research Institute, Forestry and Timber Bureau: Canberra, Australia, 1967.

6. Burrows, N.D. Experimental Development of a Fire Management Model for Jarrah (Eucalyptus marginata donn ex sm.) Forest. Ph.D. Thesis, Australian National University, Canberra, Australia, 1994.

7. Catchpole, W.R.; Wheeler, C.J. Estimating plant biomass: A review of techniques. Aust. J. Ecol. 1992, 17, 121-131. [CrossRef]

8. Price, O.F.; Gordon, C.E. The potential for lidar technology to map fire fuel hazard over large areas of australian forest. J. Environ. Manag. 2016, 181, 663-673. [CrossRef] [PubMed]

9. Van Wagner, C.E. The line intersect method in forest fuel sampling. For. Sci. 1968, 14, $20-26$.

10. Lydersen, J.M.; Collins, B.M.; Knapp, E.E.; Roller, G.B.; Stephens, S. Relating fuel loads to overstorey structure and composition in a fire-excluded sierra nevada mixed conifer forest. Int. J. Wildland Fire 2015, 24, 484-494. [CrossRef]

11. Sandberg, D.V.; Ottmar, R.D.; Cushon, G.H. Characterizing fuels in the 21st century. Int. J. Wildland Fire 2001, 10, 381-387. [CrossRef]

12. Wright, C.S.; Ottmar, R.D.; Vihnanek, R.E. Critique of sikkink and keane's comparison of surface fuel sampling techniques. Int. J. Wildland Fire 2010, 19, 374-376. [CrossRef]

13. Keane, R.E. Describing wildland surface fuel loading for fire management: A review of approaches, methods and systems. Int. J. Wildland Fire 2013, 22, 51-62. [CrossRef]

14. Sikkink, P.G.; Keane, R.E. A comparison of five sampling techniques to estimate surface fuel loading in montane forests. Int. J. Wildland Fire 2008, 17, 363-379. [CrossRef]

15. Watson, P.J.; Penman, S.H.; Bradstock, R.A. A comparison of bushfire fuel hazard assessors and assessment methods in dry sclerophyll forest near sydney, australia. Int. J. Wildland Fire 2012, 21, 755-763. [CrossRef]

16. Hines, F.; Tolhurst, K.G.; Wilson, A.A.; McCarthy, G.J. Overall Fuel Hazard Assessment Guide; Victorian Government Department of Sustainability and Environment: Melbourne, Australia, 2010.

17. Gould, J.S.; McCaw, W.L.; Cheney, N.P.; Ellis, P.F.; Knight, I.K.; Sullivan, A.L. Project Vesta: Fire in Dry Eucalypt Forest: Fuel Structure, Fuel Dynamics and Fire Behaviour; CSIRO Publishing: Clayton, Victoria, Australia, 2007.

18. Tolhurst, K.; Shields, B.; Chong, D. Phoenix: Development and application of a bushfire risk management tool. Aust. J. Emerg. Manag. 2008, 23, 47-54.

19. Cheney, N.P.; Gould, J.S.; McCaw, W.L.; Anderson, W.R. Predicting fire behaviour in dry eucalypt forest in southern australia. For. Ecol. Manag. 2012, 280, 120-131. [CrossRef]

20. Volkova, L.; Sullivan, A.L.; Roxburgh, S.H.; Weston, C.J. Visual assessments of fuel loads are poorly related to destructively sampled fuel loads in eucalypt forests. Int. J. Wildland Fire 2016, 25, 1193. [CrossRef]

21. Thomas, P.B.; Watson, P.J.; Bradstock, R.A.; Penman, T.D.; Price, O.F. Modelling surface fine fuel dynamics across climate gradients in eucalypt forests of south-eastern australia. Ecography 2014, 37, 827-837. [CrossRef] 
22. Cheal, D.C. Growth Stages and Tolerable Fire Intervals For Victoria's Native Vegetation Data Sets. Fire and Adaptive Management; Victorian Government Department of Sustainability and Environment: Melbourne, Australia, 2010.

23. Swan, M.; Christie, F.; Sitters, H.; York, A.; Di Stefano, J. Predicting faunal fire responses in heterogeneous landscapes: The role of habitat structure. Ecol. Appl. 2015, 25, 2293-2305. [CrossRef] [PubMed]

24. Sitters, H.; Christie, F.J.; Di Stefano, J.; Swan, M.; Penman, T.; Collins, P.C.; York, A. Avian responses to the diversity and configuration of fire age classes and vegetation types across a rainfall gradient. For. Ecol. Manag. 2014, 318, 13-20. [CrossRef]

25. Overall Fuel Hazard Assessment Guide. Available online: https://www.ffm.vic.gov.au/_data/assets/pdf_ file/0005/21110/Report-82-overall-fuel-assess-guide-4th-ed.pdf (accessed on 1 August 2017).

26. McColl-Gausden, S.C.; Penman, T.D. Field Data Associated with “Visual Assessment of Surface Fuel Loads Does Not Align with Destructively Sampled Aurface Fuels". Available online: https://figshare.com/ articles/McColl-Gausden_fielddata_xlsx/5413057 (accessed on 27 October 2017).

27. Walshe, T.; Wintle, B.; Fidler, F.; Burgman, M. Use of confidence intervals to demonstrate performance against forest management standards. For. Ecol. Manag. 2007, 247, 237-245. [CrossRef]

28. Sokal, R.R.; Rohlf, F.J. Biometry, 3rd ed.; W.H. Freeman and Company: New York, NY, USA, 1995.

29. R Development Core Team. R: A Language and Environment for Statistical Computing; R Foundation for Statistical Computing: Vienna, Austria, 2016.

30. Noble, I.R.; Bary, G.A.V.; Gill, A.M. Mcarthur's fire-danger meters expressed as equations. Aust. J. Ecol. 1980, 5, 201-203. [CrossRef]

31. Tolhurst, K.G.; Chong, D.M.O. Assessing potential house losses using phoenix rapidfire. In Bushfire CRC \& AFAC 2011 Conference Science Day; Thornton, R.P., Ed.; Bushfire CRC: Sydney, Australia, 2011; pp. 74-86.

32. Gill, A.M.; Christian, K.R.; Moore, P.H.R.; Forrester, R.I. Bushfire incidence, fire hazard and fuel reduction burning. Aust. J. Ecol. 1987, 12, 299-306. [CrossRef]

33. Jenkins, M.; Collins, L.; Price, O.; Penman, T.; Zylstra, P.; Horsey, B.; Bradstock, R. Environmental values and fire hazard of eucalypt plantings. Ecosphere 2016, 7, e01528. [CrossRef]

34. Collins, L.; Penman, T.D.; Price, O.F.; Bradstock, R.A. Adding fuel to the fire? Revegetation influences wildfire size and intensity. J. Environ. Manag. 2015, 150, 196-205. [CrossRef] [PubMed]

35. Penman, T.D.; Bradstock, R.A.; Price, O.F. Reducing wildfire risk to urban developments: Simulation of cost-effective fuel treatment solutions in south eastern australia. Environ. Model. Softw. 2014, 52, 166-175. [CrossRef]

36. DEWLP. Strategic Bushfire Risk Management Plan-Barwon Otway; Department-of-Environment-Land-Waterand-Planning, Ed.; Victorian Government Department of Environment and Primary Industries Melbourne: Melbourne, Australia, 2015; p. 42.

37. Etienne, R.S.; Vos, C.C.; Jansen, M.J.W. Ecological impact assessment in data-poor systems: A case study on metapopulation persistence. Environ. Manag. 2003, 32, 760-777.

38. Keith, D.W. When is it appropriate to combine expert judgments? Clim. Chang. 1996, 33, 139-143. [CrossRef]

39. Runge, M.C.; Converse, S.J.; Lyons, J.E. Which uncertainty? Using expert elicitation and expected value of information to design an adaptive program. Biol. Conserv. 2011, 144, 1214-1223. [CrossRef]

40. Krueger, T.; Page, T.; Hubacek, K.; Smith, L.; Hiscock, K. The role of expert opinion in environmental modelling. Environ. Model. Softw. 2012, 36, 4-18. [CrossRef]

41. Burgman, M.A.; McBride, M.; Ashton, R.; Speirs-Bridge, A.; Flander, L.; Wintle, B.; Fidler, F.; Rumpff, L.; Twardy, C. Expert status and performance. PLoS ONE 2011, 6. [CrossRef] [PubMed]

42. Wintle, B.C.; Fidler, F.; Vesk, P.A.; Moore, J.L. Improving visual estimation through active feedback. Methods Ecol. Evol. 2013, 4, 53-62. [CrossRef]

(C) 2017 by the authors. Licensee MDPI, Basel, Switzerland. This article is an open access article distributed under the terms and conditions of the Creative Commons Attribution (CC BY) license (http:/ / creativecommons.org/licenses/by/4.0/). 